\title{
Perguntas e respostas nos liuros didáticos: desconstruindo estereótipos
}

Questions and answers in the textbooks: Deconstructing stereotypes

Fernanda Bueno Sain't Clair

FFP/UERJ

Victoria Wilson da Costa Coelho

FFP/UERJ

DOI: https://doi.org/10.5902/2176148535858

Resumo: Este artigo, fruto de uma pesquisa desenvolvida na área de Linguística Aplicada, no Mestrado Profissional (PROFLETRAS), visa contribuir para a discussão sobre livro didático de língua portuguesa no que concerne à elaboração de perguntas e à projeção de respostas para relacioná-las às compreensões leitoras dos alunos, com base na perspectiva discursiva da língua(gem) em interface com trabalhos no campo social da educação. 0 estudo aponta para novos (des)entendimentos, colocando em xeque a própria docência, pois mostra a desconstrução de estereótipos negativos acerca dos jovens, especialmente os das classes populares, referentes às dificuldades nas aulas de língua portuguesa.

Palavras-chave: Livro didático. Prática docente. Compreensão. Expectativas.

Abstract: This article is the result of a research developed in the Applied Linguistics area in the professional master's degree (PROFLETRAS). It aims to contribute to the discussion about Portuguese language in textbooks regarding the formulation of questions and the projection of answers in order to relate to the student's reading comprehension, based on discursive perspective of the language in interface with projects in the social field of education. The study points to new (dis)agreements, putting at stake the own teaching, as it shows the deconstruction of negative stereotypes on young people, especially the grass-roots classes ones, regarding the difficulties in the Portuguese language classes.

Keywords: Textbook. Teaching practice. Comprehension. Expectations 
Fernanda Bueno

Sain't Clair

Victoria Wilson

da Costa Coelho

278

\section{Introdução}

Esse artigo propõe uma reflexão sobre a prática docente a partir da compreensão leitora dos alunos em relação às formulações das questões do tipo pergunta-resposta em livros didáticos. A pesquisa centrou-se na observação e análise do modo como os alunos apreendem os enunciados propostos e como constroem discursivamente suas respostas. Na busca de empreender essa reflexão, procurou-se observar as vivências e os conhecimentos dos alunos e, dessa maneira, estender a reflexão à própria prática docente ${ }^{1}$.

A pesquisa foi desenvolvida em uma escola pública, localizada em um bairro periférico do município de São Gonçalo, Estado do Rio de Janeiro. A experiência na escola pública fez crescer o desejo de compreender aquele espaço, aqueles alunos e o papel da professora diante de um cenário povoado de conflitos, inquietudes, angústias e incertezas, decorrentes não só das questões sociais que afetam o ensino na escola pública, em geral, como também das dificuldades encontradas no processo de compreensão de leitura dos alunos, em particular. A angústia por não entender por que os alunos apresentam tanta dificuldade e/ ou resistência ou, muitas vezes, não conseguem responder enunciados das questões, ainda que aparentemente muito simples, foi a motivação desse estudo.

As questões que orientaram, inicialmente, a pesquisa, giram em torno dos seguintes eixos: Por que os alunos têm dificuldade em compreender formulações de enunciados de questões? Qual seria a origem dessa dificuldade? Que fatores são atribuídos a essa dificuldade? E o que, de fato, eles não compreendem?

Tais indagações conduziram a reflexões que acabaram por reformular a perspectiva segundo a qual a incompreensão ou a falta de conhecimento para responder às questões estariam vinculadas apenas às dificuldades dos alunos, reforçando assim a natureza unilateral do fracasso escolar. Portanto, ao invés de reproduzir a naturalização do fracasso escolar centrado no aluno, foram levantadas outras questões, a saber: As respostas às questões formuladas para os alunos e esperadas pelos professores (e pela própria professora, sujeito dessa pesquisa) afe-

\footnotetext{
1 Esse artigo é fruto de reflexões que integram a pesquisa desenvolvida no curso de Mestrado Profissional em Letras - PROFLETRAS, realizado na Faculdade de Formação de Professores da UERJ (FFP-UERJ) de que se originou a dissertação de mestrado. Neste trabalho, foram realizados recortes, produzidas algumas reformulações e adaptações para efeito de publicação em artigo.
} 
tam a avaliação sobre a compreensão dos alunos? Que expectativas são criadas pelos professores em relação às respostas dos alunos? E o que tais expectativas influenciam e/ou conduzem a um (des)entendimento do processo de ensino e de aprendizagem no sentido de reproduzir estereótipos negativos acerca das crianças e jovens especialmente os das classes populares?

Diante dos dilemas que se impuseram a partir dessas novas indagações, a pesquisa rumou para a investigação do modo como são incorporados os saberes e as linguagens escolares pelos alunos para procurar demonstrar que "o fracasso escolar não é um problema linguístico, mas semiótico" (STUBBS, 2002, p. 113).

$\mathrm{O}$ artigo está distribuído em três seções. Na primeira, delineia-se o cenário da pesquisa e os rumos do fazer-docente no contexto da pes-

Perguntas e respostas nos livros didáticos: quisa; na segunda, apresenta-se a análise do material composto por um modelo de perguntas-respostas; e na terceira seção, são apresentados os resultados da análise com a reflexão acerca da prática docente e do próprio fazer da pesquisa.

\section{0 cenário da pesquisa}

\subsection{A escola}

O trabalho foi realizado em uma escola da rede estadual do município de São Gonçalo, em que a professora atua como docente de língua portuguesa e produção de textos ${ }^{2}$. A escolha por essa escola se deu por dois motivos: o primeiro relaciona-se à identificação pessoal da professora com a instituição, pois foi o local onde teve início seu exercício no magistério; o segundo está vinculado à experiência de trabalho com turmas do $6^{\circ}$ ano.

A escola está localizada às margens da Rodovia Amaral Peixoto (RJ - 104), no 3ํ distrito, entre os bairros do Jardim Catarina e o Laranjal, ambos no município de São Gonçalo. A instituição possui 1100 alunos, oriundos de bairros do entorno, divididos desde o $6^{\circ}$ ano do Ensino Fundamental até a $3^{\mathrm{a}}$ série do Ensino Médio, nos três turnos: manhã, tarde e noite, além de possuir turmas de aceleração e reforço escolar para $6^{\circ}$ e $9^{\circ}$ anos.

Jardim Catarina, bairro onde se localiza a escola e onde reside a maior parte dos alunos, tem grande concentração populacional, e é basicamente composto por casas e pequenos comércios e com poucos

2 A professora da turma atuou como docente-pesquisadora. 
recursos e atrativos culturais e de lazer. Em Periferia e Espaços Periféricos: um estudo de caso do loteamento Jardim Catarina, Leandro Guimarães (2015) afirma que

Fernanda Bueno

Sain't Clair

Victoria Wilson

da Costa Coelho

o Jardim Catarina é um retrato do histórico do modelo brasileiro de urbano-industrialização, onde a produção, ocupação e reprodução do solo urbano brasileiro baseou-se na periferização e centralização dos recursos e da pobreza, o que resultou na construção das áreas periféricas brasileiras (GUIMARÃES, 2015, p. 241).

Nesse bairro periférico em que espaços de lazer são inexistentes, há "uma similitude de histórias e de presenças em que grande parte das histórias de vida repetem-se", (GUIMARÃES, 2015, p.240). Na confluência de histórias, ausências e presenças integradas à periferização encontra-se a escola, a professora e os alunos.

\subsection{A abordagem metodológica}

A metodologia que norteou esta pesquisa centrou-se no espaço escolar, em sua dinâmica, em seu estar pulsante, de maneira que o trabalho fosse encaminhado de modo a tratar da complexidade das questões expostas enfrentando-as experiencialmente. A opção pela pesquisa etnográfica e a pesquisa-ação deve-se ao fato de que a primeira, segundo André (1995), possibilita

\footnotetext{
que se chegue bem perto da escola para tentar entender como operam no seu dia a dia os mecanismos de dominação e resistência, de opressão e de contestação ao mesmo tempo em que são veiculados e reelaborados conhecimentos, atitudes, valores, crenças, modos de ver e de sentir a realidade e o mundo (ANDRÉ, 1995, p. 41).
}

Na pesquisa-ação, conforme Dionne (2007), procuram-se aliar dois processos: a abordagem científica e a abordagem da ação em si mesma. Essa aliança provoca "uma redução da distância entre a teoria e a prática", [o que acaba por levar o pesquisador] "a tomar em consideração, de modo mais aprofundado, o vivido dos atores e participantes e de fornecer explicações pertinentes para a ação" (DIONNE, 2007, p.27). 
O objetivo primeiro da pesquisa-ação "é mudar uma dada situação particular levando em consideração a totalidade concreta tal como é vivida. Se não fosse assim, por que falar em pesquisaação?" (DIONNE, 2007, p. 23-7). Neste tipo de pesquisa, espera-se que haja uma revisão ou um tipo de reeducação de comportamentos, por isso, a pesquisa-ação assume um caráter coletivo, de cooperação mútua entre os participantes em busca de explicações e soluções para seus problemas.

$\mathrm{Na}$ construção da pesquisa, a práxis da professora foi se remodelando à medida em que procurava olhar os alunos através das lentes usadas por eles. A partir dessa nova forma de "ver", atitudes foram sendo alteradas de modo que a pesquisa e as próprias interações em sala de aula foram se reajustando no decorrer das aulas. Durante todo o per-

Perguntas e respostas nos livros didáticos: curso trilhado, as atividades trabalhadas foram revistas e (re) avaliadas, reafirmando a proximidade com os alunos para inseri-los ativamente na práxis escolar.

Considerando a sala de aula como um espaço social e o professor como mediador desse espaço, renovaram-se significados e criaram-se sentidos, com abertura para novas descobertas e para que outras compreensões da sala de aula se tornassem possíveis, tornando o ensino de língua portuguesa uma atividade mais reflexiva e produtiva, tomando por base a seguinte questão ou princípio: “(...) como lidar com a diferença com base na compreensão de nós mesmos como outros" (MOITA LOPES, 2014, p. 89)

\subsection{A sala de aula: as relações entre a professora e os alunos}

A turma, composta por 24 alunos, cuja média de idade variava entre 12 e 15 anos, ou seja, uma média um pouco acima para esse ano de escolaridade, era agitada e barulhenta como toda turma de adolescentes. ${ }^{3}$

Trabalhar leitura e compreensão de textos de forma a atrair os alunos era uma tarefa complicada. Além de todos os problemas estruturais da escola tais como a falta de material, as salas escuras, a biblioteca funcionando de modo precário, somavam-se as dificuldades no decorrer da aula: a maior parte dos alunos não demonstrava desejo nem de ler nem de realizar nada do que era proposto pela professora.

3 Os alunos, inicialmente, comportavam-se de forma descompromissada, sem demonstrar interesse em aprender e com o discurso do fracasso na ponta da língua. 
Fernanda Bueno

Sain't Clair

Victoria Wilson

da Costa Coelho

Diante desse cenário, foi necessário rever a interação estabelecida em aula e gerar novas condutas de ação que provocassem também mudanças de comportamento entre os alunos. Além de propiciar com as novas condutas adotadas um sentimento de pertencimento do aluno em relação à escola, houve uma proposta de reordenação do espaço e da dinâmica da sala de aula. As aulas tornaram-se diferentes: foram realizados lanches e festas; os alunos ouviram música, pintaram, desenharam; organizaram feiras multidisciplinares, show de talentos, mas também "estudaram". E a cada semana, foram criados laços de amizade cada vez mais fortes, estabelecendo uma parceria entre nós, ainda que nem todos partilhassem de forma integrada àqueles momentos. A aproximação com a turma não apagou as tensões existentes, mas redimensionou as práticas de ambos os atores/agentes do processo, fruto de um trabalho em que se tornou:

\footnotetext{
(...) necessário entender o ambiente escolar no qual estava inserida, o perfil dos meus alunos e o meu papel naquela instituição. Para mim, era importante dar sentido à minha atuação na prática docente e esse sentido só era possível com a colaboração dos meus alunos, já que eles integravam tal prática (SAINT' CLAIR, 2016, p. 19)
}

Com as mudanças ocorridas, constatou-se que era necessário um fazer docente ainda mais comprometido, em que não era mais possível fechar os olhos e tapar os ouvidos para tantas histórias, tantas vozes que ali ecoavam; era imperioso perceber e trabalhar as singularidades: "afirmar que são Outros não é suficiente, o desafiante é com que olhar os vemos e como se veem" (ARROYO, 2011, p. 225). Nessa busca por um fazer docente mais comprometido, tentava-se também conciliar as exigências do Currículo Mínimo aos interesses dos alunos.

\section{Ações em sala de aula: novos rumos na prática docente?}

Diante de tantas questões que envolvem o ensino de língua e a própria natureza da escola, com suas tensões, significados e particularidades, foi realizado um planejamento de modo que os objetivos traçados no início do ano letivo pudessem ser alcançados. O planejamento inicial 
ora contemplava o Currículo Mínimo ${ }^{4}(\mathrm{CM})$, ora os conteúdos do livro didático ${ }^{5}$, uma vez que ambos não seguiam a mesma sequência.

Durante as aulas, as dificuldades de compreensão eram observadas, mas, inicialmente, não eram computadas como incompreensões também da própria professora em relação às formas de compreensão dos alunos, pois ancoravam-se nas expectativas docentes e escolares. No entanto, essa situação começou a se alterar a partir do momento em que foi possível observar o modo como os alunos articulavam seus próprios conhecimentos (de mundo e escolares) para construir suas respostas.

Outras respostas, além das idealizadas pela professora, poderiam ser possíveis, dependendo do momento de sua produção e da intenção dos enunciados. As respostas estavam ali, e só depois de reverter as expectativas prévias foi possível perceber, ouvir os alunos e enxergar os

Perguntas e respostas nos livros didáticos: múltiplos sentidos que eles davam aos textos.

Para dar um rumo diferente a essa caminhada foi necessário conhecer alguns conceitos essenciais para a melhoria da qualidade das aulas como a ampliação dos saberes dos alunos, com atividades mais "responsivas", em que eles e a professora pudessem coconstruir suas práticas escolares. Não há ensino sem escuta, não há aprendizagem construída em silêncio absoluto. Não há entendimento de um texto sem uma pequena intimidade com aquilo que é oferecido e, sem intimidade, haverá apenas o reconhecimento (e não a compreensão) de termos e estruturas lexicais. Nos termos do pensamento bakhtiniano, nesse caso, estamos promovendo apenas a identificação do sinal, pois a compreensão se manifesta na esfera do signo (ideológico), conforme lemos em Volochinov:

A compreensão passiva caracteriza-se justamente por uma nítida percepção do componente normativo do signo linguístico, isto é, pela percepção do signo como um objeto-sinal: correlativamente, o reconhecimento predomina sobre a compreensão (VOLOCHINOV, 2014, 102)

\footnotetext{
4 Esse documento foi organizado pela Secretaria de Educação do Estado do Rio de Janeiro (SEEDUC) e norteia os caminhos curriculares do professor, apresentando competências e habilidades para os anos de escolaridade. $O$ projeto do Currículo Mínimo, ancorado nos Parâmetros Curriculares Nacionais (PCN) e nas Leis de Diretrizes e Bases (LDB), vem sendo desenvolvido desde 2006, numa tentativa de aproximar a sala de aula aos componentes curriculares. Para essa pesquisa utilizei a última versão, do ano de 2012. 5 O livro didático adotado pela escola é "Português Linguagens", de autoria de William Roberto Cereja e Thereza Cochar Magalhães. O exemplar utilizado corresponde ao PNLD dos anos de 2014, 2015 e 2016. 6 Para Bakhtin, a língua é constitutivamente dialógica e, é a partir desse dialogismo que os discursos são produzidos, assim como as respostas dos alunos. Desse modo, tudo é que respondido pelo aluno é uma resposta a algo já produzido anteriormente ou uma tentativa de dialogar com o que ainda será produzido.
} 


\section{Fernanda Bueno}

Sain't Clair

Victoria Wilson da Costa Coelho

A apreensão dos sentidos na leitura não é tão somente mediada pelo próprio texto, mas pelas relações que o leitor faz com outros sujeitos implícitos e outros saberes na situação discursiva. O sentido de um texto vai sendo criado a partir de sua leitura, num processo simultâneo, "sujeitos e sentidos são elementos de um mesmo processo, o da significação" (ORLANDI, 1993, p. 10). Nessa perspectiva, há diversos modos de um leitor relacionar-se com o texto, enfatizando a interação com o autor, com outros textos, com o contexto, com o próprio leitor, seja esse leitor, ele mesmo ou um outro. A partir dessa nova compreensão ativo-responsiva do enunciado, foram ressignificadas as práticas docentes com os alunos dessa turma em busca de novas compreensões das dificuldades ocorridas nas aulas. Como afirma Arroyo: "Somente mirando esses adolescentes e jovens nesse olhar aberto entenderemos quem são nas salas de aula: os mesmos vistos como incômodos fora" (ARROYO, 2011, p. 224).

Por essa razão, a escola não deve atribuir o fracasso aos alunos, já que "Decretá-los in-incluíveis é um atestado de fracasso não tanto deles, mas das promessas mais caras à escola e às políticas educativas: a inclusão social pela escolarização" (ARROYO, 2011, p. 227). As ações docentes são limitadas e os professores integram apenas uma parte desse sistema, entretanto, o professor pode contribuir para a desnaturalização de determinadas práticas em sala de aula, tais como: excessivas reprovações, silenciamento de práticas de letramento dos alunos e respeito às suas vivências. Isto posto, fica claro que se a responsabilidade do fracasso escolar recai somente sobre os alunos, estaremos perpetuando padrões de comportamento que excluem da rede de relações outros responsáveis pelo fracasso escolar: os próprios professores; o sistema curricular; as instituições e todo o conjunto da sociedade.

Nessa perspectiva, no que tange ao ensino da língua, Geraldi (2015) afirma que os alunos não devem aprender a língua padrão para ter acesso à cidadania, mas "construir a linguagem da cidadania, não pelo esquecimento da 'cultura elaborada', mas pela reelaboração de uma cultura (inclusive linguística) resultante do confronto dialógico entre diferentes posições" (GERALDI, 2015, p. 37). Assim, as atividades em sala de aula devem contribuir para a construção do conhecimento partilhado em atenção às linguagens e aos conhecimentos que integram as experiências dos alunos.

Sabe-se que a escola, possivelmente, proporcionará o domínio de habilidades de letramento e de noções de diversos conteúdos curriculares, entretanto, pode-se mudar a maneira como os alunos vivem o am- 
biente da sala de aula, como se relacionam, mudar o próprio entendimento de letramento com vistas à assunção do modelo ideológico ${ }^{7}$ a fim de "reconhecer que o direito ao conhecimento socialmente produzido não se esgota no conhecimento escolar" (ARROYO, 2011, p. 123). A diversidade de experiências pode ampliar os saberes escolares e viabilizar uma nova organização curricular em que os professores também substituirão práticas muitas vezes passivas (como transmissores de conhecimento) para assumir um lugar de (co)produtores de conhecimento. Como bem argumenta Arroyo (2013) em relação aos professores: "não se aceitarem como passivos é um dos avanços mais esperançadores no fazer educativo e nos processos de aprender" (ARROYO, 2011, p. 153).

Assim, a partir da compreensão do modo como os alunos se relacionam com o mundo que os cerca, os professores podem contribuir

Perguntas e respostas nos livros didáticos: para a construção de uma linguagem cidadã, possibilitando uma real atuação na sociedade, reconhecendo o seu lugar, suas origens e valorizando os seus saberes e os saberes oriundos da escola.

\section{0 livro didático:}

\section{perguntas, respostas e procedimentos de análise}

\subsection{Professora, as perguntas são muito difíceis!}

O livro didático utilizado na escola, de onde foram selecionadas as perguntas com as respostas dos alunos, denomina-se "Português Linguagens", de autoria de William Roberto Cereja e Thereza Cochar Magalhães, referente ao $6^{\circ}$ ano. Trata-se de uma coleção muito difundida nas escolas brasileiras com um nível de aceitação favorável entre os professores. 0 exemplar escolhido para o trabalho corresponde ao PNLD dos anos 2014, 2015 e 2016.

o livro organiza-se em quatro unidades e cada unidade é dividida em três capítulos. Tais capítulos apresentam algumas seções principais, como: "Estudo do texto", "Produção de texto" e "Língua em foco". Há outras seções que compõem a obra, mas não estão presentes em todos os capítulos, a saber: "Para escrever com expressividade", "De olho na escrita", "Divirta-se", "Para escrever com adequação", "Para escrever com coesão e coerência" e "Intervalo".

7 Para Street (2014), o modelo ideológico do letramento tem em vista práticas sociais de leitura e escrita que não excluem habilidades e tecnologias, mas enfatizam o modo como cada grupo lida com, compreende e dá sentido às atividades de leitura e escrita, observando-se o conjunto de fatores (políticos, econômicos, ideológicos, etc.) que atuam favoravelmente ou não no processo de aquisição, (des) incorporação e aprendizagem. 
Fernanda Bueno

Sain't Clair

Victoria Wilson

da Costa Coelho

286
As questões analisadas neste trabalho correspondem à primeira unidade do livro, na seção designada "Língua em foco". Todas as questões são introduzidas pela expressão Construindo o Conceito, o que sugere tratar-se de questões com baixo índice de complexidade. 0 texto que abre essa seção é uma anedota - texto curto, com uma estrutura narrativa, semelhante a uma piada -, seguida de quatro atividades baseadas no gênero em pauta. As atividades relacionadas à anedota foram priorizadas para o trabalho inicial com os alunos, porque foram consideradas simples do ponto de vista da compreensão.

As perguntas da atividade do livro foram respondidas pelos alunos durante as aulas. Para esse trabalho, foi selecionada apenas uma das perguntas realizadas com as respectivas respostas dos alunos, num total de cinco respostas. Abaixo, destaca-se toda a atividade da seção do LD para contextualizá-la no conjunto das questões.

1. Observe a situação em que se dá o diálogo entre pai e filho.

a) Trata-se de uma situação formal ou informal? Por quê?

b) A situação parece estar tensa ou descontraída?

2. Márcio diz ao pai que vai lhe dar uma ótima notícia.

a) Com que finalidade o garoto diz isso ao pai?

b) Em sua opinião, por que o garoto agiu dessa maneira?

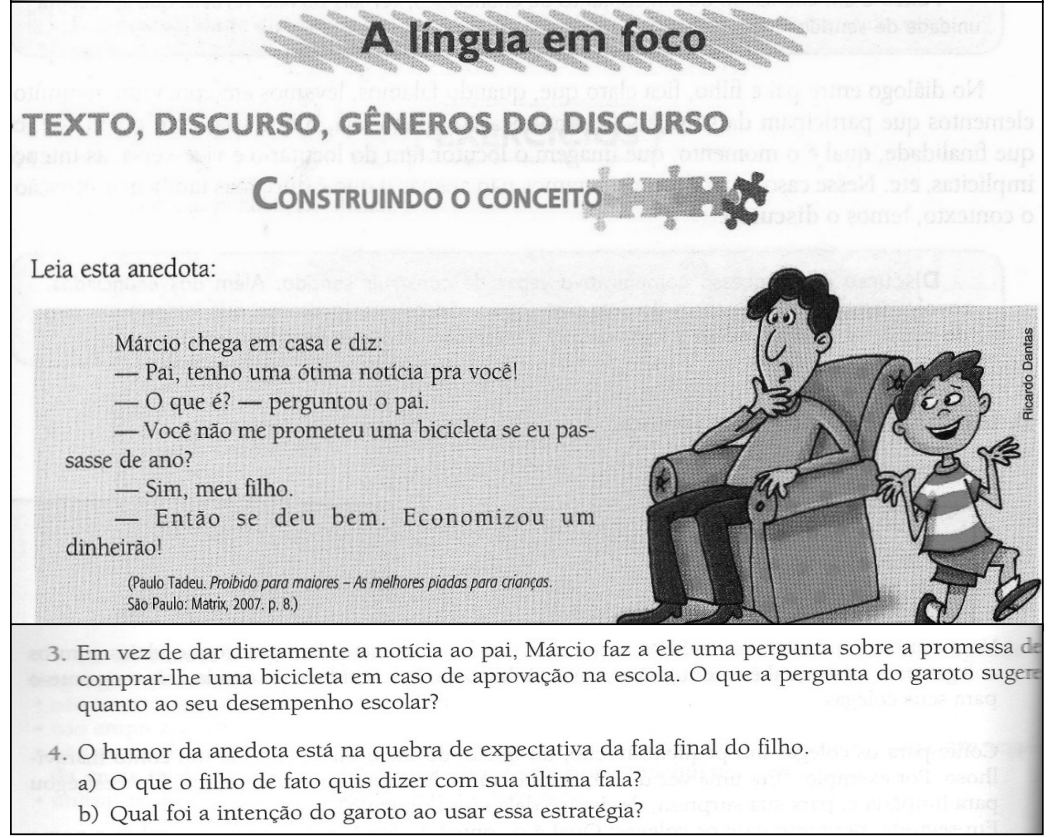

FIGURA 1 - Texto e atividades do livro didático

Fonte: Português Linguagens $-6^{\circ}$ ano 
Com o intuito de compreender as perguntas formuladas pelo LD, foram utilizadas as categorias que Marcuschi (2003) estabeleceu para os tipos de perguntas formuladas em materiais didáticos, tais como: a cor do cavalo branco de Napoleão, cópias, objetivas, inferenciais, globais, subjetivas, vale-tudo, impossíveis e metalinguísticas.

Além dessa categorização, a análise das perguntas, considerando-se as respostas dos alunos, está baseada em concepções de leitura e legibilidade e na compreensão de textos segundo a perspectiva discursiva de origem bakhtiniana. A análise das perguntas e das respostas também estará apoiada nos pressupostos de Paulo Freire. Para ampliar a discussão é importante observar a associação entre os saberes e linguagens escolares com os conhecimentos do cotidiano e os conhecimentos prévios dos alunos, além das ações com e sobre a linguagem em

Perguntas e respostas nos livros didáticos: busca da compreensão dos enunciados propostos, como formulados por Geraldi (2013), considerando-se o horizonte do professor e o horizonte do aluno no espaço escolar conforme Goulart (2009). Sobre as questões envolvidas nos saberes para as e das classes populares, Arroyo (2011; 2012) e Freire (2002) contribuíram para a reflexão crítica dos processos de compreensão, legibilidade e poder implicados no processo de ensino e da aprendizagem, como sintetizado abaixo:

\footnotetext{
Por isso mesmo pensar certo coloca ao professor ou, mais amplamente, à escola, o dever de não só respeitar os saberes com que os educandos, sobretudo os das classes populares, chegam a ela - saberes socialmente construídos na prática comunitária - mas também, como há mais de trinta anos venho sugerindo, discutir com os alunos a razão de ser de alguns desses saberes em relação com o ensino dos conteúdos (FREIRE, 2002, p. 33).
}

Entender que as respostas que os alunos produzem apresentam uma multiplicidade de sentidos não é uma tarefa simples, mas torna-se imprescindível no fazer-docente. Reconhecer os alunos como pessoas que produzem conhecimentos, significa também reconhecer "que todo conhecimento é uma produção social, produzido em experiências sociais e que toda experiência social produz conhecimento pode nos levar a estratégias de reconhecimento" (ARROYO, 2011, p. 117). 


\section{Fernanda Bueno}

Sain't Clair

Victoria Wilson

da Costa Coelho

Nesse sentido, impossível hierarquizar saberes. Fazia-se mister compreendê-los na dinâmica das interações, conferindo-lhes a importância devida. Reconhecer os saberes e assumir formas de comportamento e ação voltados para a assunção e o compartilhamento da multiplicidade de saberes que convergem na e para a sala de aula tornou-se uma valiosa forma (atitude) de ver o mundo e entender os alunos. Como propõe Paulo Freire: "Somente quem escuta paciente e criticamente o outro, fala com ele, mesmo que, em certas condições, precise falar a ele" (grifos do autor) (FREIRE, 2002, p. 128).

São essas reflexões, reconhecimentos, que proporcionam uma docência mais sensível, acreditando que a cada aula é possível constatar que as respostas dos alunos são baseadas em seus conhecimentos, em suas tentativas de acerto e projeções de expectativas escolares, ou seja, respostas possíveis, porém, nem sempre desejáveis. Ainda que haja incoerências, dúvidas e dificuldades no processo de ensino-aprendizagem, são essas vivências que fazem parte da realidade escolar, afinal, não há escola, não há aprendizagem, sem erro, sem conflito e sem tensão. Como afirma Arroyo (2011):

\footnotetext{
Essa tensão chega aos currículos pressionados para reconhecer a diversidade de experiências e de conhecimentos e a diversidade de sujeitos que chegam às escolas, carregando suas experiências e seus conhecimentos (ARROYO, 2011, p. 117).
}

Na seção seguinte, serão analisadas as respostas dos alunos, selecionadas nesse artigo.

\subsection{Professora, a minha resposta está errada?}

As várias formas de ler uma pergunta e a produção de diversas respostas partindo de conhecimentos de sujeitos outros são marcantes dentro da construção de um novo fazer-docente. Na análise, será observada a articulação entre a pergunta e a resposta, com base nos pressupostos trabalhados, ou seja, o dialogismo e as práticas de letramento.

Passemos à questão três e às respostas dadas pelos alunos para proceder à análise: 
3. Em vez de dar diretamente a notícia ao pai, Márcio faz a ele uma pergunta sobre a promessa d comprar-lhe uma bicicleta em caso de aprovação na escola. O que a pergunta do garoto suge quanto ao seu desempenho escolar?

4. O humor da anedota está na quebra de expectativa da fala final do filho

a) $\mathrm{O}$ que o filho de fato quis dizer com sua última fala?

b) Qual foi a intenção do garoto ao usar essa estratégia?

FIGURA 2 - Questão 3

Fonte: Português Linguagens $-6^{\circ}$ ano

\begin{tabular}{|l|l|}
\hline \multicolumn{2}{|c|}{ RESPOSTAS } \\
\hline Aluno 1 & Se eu passasse de ano. \\
\hline Aluno 2 & Ao desempenho mínimo. \\
\hline Aluno 3 & Que ele economizou o dinheiro da bicicleta. \\
\hline Aluno 4 & Que ele não foi reprovado na escola. \\
\hline Aluno 5 & Se eu passasse de ano. \\
\hline
\end{tabular}

Perguntas

e respostas

nos livros

didáticos:

A questão três, como se pode notar, possui densidade informacional e complexidade quanto à sua estrutura: trata-se de uma afirmação relativamente longa, ordenada de modo inverso, com o emprego de muitos pronomes que substituem elementos importantes para a compreensão da questão como um todo. A questão suscita uma leitura mais lenta e atenta, por parte dos alunos, pois requer maior elaboração, uma vez que é necessário percorrer todo um caminho até chegar à pergunta em si, pois se trata de uma pergunta do tipo inferencial. No que se refere ao tema da questão, havíamos compreendido tratar-se de um assunto familiar às experiências do cotidiano dos alunos, o que não constituiria um fator dificultador, ao contrário.

De acordo com as respostas dadas, no entanto, foi possível observar que os alunos imaginaram e atribuíram sentidos diferentes ao enunciado proposto e a todo o conjunto da anedota. As compreensões dos alunos não foram sentidas como coerentes, à primeira vista, pois não estavam se alinhado à resposta prevista, a saber: "Sugere que o desempenho escolar do menino foi satisfatório, de acordo com o esperado pelo pai."

O que fazer, então, diante de respostas tão inusitadas? Como avaliar as respostas dos alunos, tendo em vista a multiplicidade de saberes e vivências que precisa ser acolhida (e não negada ou negligenciada) em sala de aula pelos professores? Essa situação tornou-se um dilema e um desafio para lidar com novos modos de compreensão, provocando uma mudança de ação na práxis docente. 
Fernanda Bueno

Sain't Clair

Victoria Wilson

da Costa Coelho

Primeiramente, reconhecer que a ausência de um conhecimento prévio é um fator que dificulta a compreensão do texto e das questões que o seguem. Apesar de os exercícios constarem como atividades introdutórias ao assunto a ser trabalhado, solicitavam saberes escolares distantes dos alunos naquele momento, devido aos fatores mencionados anteriormente: grau de densidade e complexidade informacional e estrutural da questão. Se a compreensão, diferentemente, da decodificação, se constrói num processo dialógico e ideológico, pode-se concluir que o trabalho do professor deve levar em conta a natureza do conhecimento linguístico e os elementos que não estão explícitos ou previamente definidos e que, porventura, podem prejudicar a compreensão dos alunos, afastando-os de repostas coerentes e levando-os a produzir respostas outras.

Sobre as respostas dos alunos 1 e 5: "se eu passasse de ano", pode-se pensar que, possivelmente, eles tenham recorrido a uma cópia de um fragmento do texto. Tais alunos transcreveram um trecho que estava relacionado ao desempenho escolar do personagem Márcio, mas se tratava de uma suposição que não se confirmou ao final da anedota.

A anedota, para ser compreendida em sua totalidade, exigia do leitor alguns conhecimentos necessários para a construção de sentidos: “espera-se, da parte do leitor, que considere esses conhecimentos (de língua, de gênero textual e de mundo) no processo de leitura e construção de sentido (KOCH e ELIAS, 2014, p. 27).

Nesse caso, uma das hipóteses para respostas desse tipo pode corresponder à "estratégia de preenchimento" apenas para a reposta não ser deixada em branco. Em muitos casos, os alunos preferem escrever uma possível (ou qualquer) resposta a não responderem absolutamente nada. Por outro lado, pode-se considerar que na resposta -"se eu passasse de ano -" há uma possibilidade de inferir que Márcio pode ter passado de ano, ou não, pois se trata de um enunciado hipotético (introduzido pela conjunção se); nesse caso, a resposta atende à questão por incluir duas possibilidades de leitura, ficando a cargo do professor (leitor) resolver esse dilema.

A resposta elaborada pelos alunos comprova que os enunciados, de alguma forma, sempre produzem uma resposta, pois, na perspectiva dialógica, sempre se responde ao Outro, há sempre uma intenção discursiva de acordo com a situação: "isso não quer dizer que as intenções estejam codificadas no sistema interno dos indivíduos, mas que se trata de comportamentos responsivos às inúmeras solicitações que lhes são feitas enquanto seres sociais" (OLIVEIRA, 2008, p.81). 
Quanto aos alunos 2 e 4, suas respostas consideraram o desempenho de Márcio no ano escolar: a resposta do aluno 2 estava orientada para o mau desempenho: "ao desempenho mínimo"; já o aluno 4 afirmou que Márcio não foi reprovado na escola. Não há como negar que o aluno 2, mesmo escrevendo uma resposta, de certo modo, incompleta, tenha entendido a anedota $\mathrm{e}$, assim, inferido que o menino não obteve um bom resultado escolar. Talvez, a dificuldade com o entendimento da própria questão tenha colaborado para esse tipo de resposta em que o aluno por falta de experiência e familiaridade com trabalhos de leitura e compreensão de texto na escola se vê impossibilitado de responder de forma a dar sentido a suas respostas. Para Koch e Elias,

Perguntas e respostas nos livros didáticos:

Quanto ao aluno 3, diferentemente dos demais, não relacionou o desempenho do menino ao seu sucesso ou fracasso escolar, mas a possibilidade de o pai economizar o dinheiro da bicicleta. Observe: "Que ele economizou o dinheiro da bicicleta".

Ao responder sobre a economia que o pai faria, o aluno respondeu, de forma indireta, sobre o desempenho do menino já que o pai só economizaria se o filho fosse reprovado. A partir dessa análise, constata-se que o aluno entendeu a anedota lida; talvez, não tenha construído sua resposta do modo como era esperado, já que a questão estava relacionada ao desempenho escolar de Márcio e não ao que esse desempenho produziria em termos de efeito ou resultado. Entretanto, pode-se notar coerência na resposta deste aluno, já que, de alguma forma, ele procurou atribuir algum sentido possível com base na leitura do texto. Pode-se concluir, então, que a "coerência, portanto, não está no texto, mas é construída a partir dele, com a mobilização de uma série de fatores de ordem discursiva, sociocognitiva, situacional e interacional" (KOCH \& ELIAS, 2014. p. 208), o que reforça o quanto os sentidos são construídos de maneira responsiva e dialógica. Como afirma Sobral: 
sem se conhecer o contexto, ou melhor, o que há de relevante nele para o texto, as "inferências" sobre o sentido serão prejudicadas e só se vão perceber as significações, o nível do sistema de língua, sem a contribuição do sistema de uso que são a real vida da língua (SOBRAL. 2011, p. 44)

Fernanda Bueno

Sain't Clair

Victoria Wilson

da Costa Coelho

292

Possivelmente, os alunos construíram suas respostas de acordo com as expectativas do professor-leitor, contudo perceberam diversos outros elementos verbais, ativaram conhecimentos e leram os textos de acordo com as experiências que possuíam: "as pessoas, as classes sociais, as esferas sociais do conhecimento, utilizam a língua de acordo com seus valores e conhecimentos, construídos na vida cotidiana e em outras esferas sociais" (GOULART, 2009, p. 17).

É importante destacar que as respostas produzidas pelos alunos podem invalidar, no momento da correção, os sentidos que eles atribuíram ao texto. Professores têm como prática legitimar respostas dentro do seu próprio repertório de expectativas, limitando a multiplicidade de sentidos de um texto. De acordo com Oliveira,

\footnotetext{
A pessoa está sempre na ilusão de que consegue criar um discurso próprio, de que consegue amordaçar os signos em um texto, mesmo quando percebe que os outros indivíduos tecem diferentes tramas a partir do mesmo texto. Essas representações são as “formas" do sentido, os "olhares" políticos do indivíduo sobre/ no mundo! (OLIVEIRA, 2008, p. 81).
}

Em segundo lugar, portanto, não há como não considerar as respostas dos alunos ou ficar indiferente a elas. É essencial, na prática docente, a desconstrução de crenças e certezas prévias na busca da construção de novas/outras compreensões para, então, olhar as respostas dos alunos a partir de um novo lugar, uma nova ótica. É preciso:

considerar o leitor e seus conhecimentos e que esses conhecimentos [são] diferentes de um leitor para outro implica aceitar uma pluralidade de leituras e de sentidos em relação a um mesmo texto (KOCH \& ELIAS, 2014, p. 21). 
Dessa forma, a tentativa é compreender o caminho trilhado pelo aluno em suas respostas para entender o próprio fazer pedagógico. De acordo com Kleiman (2011), uma possível solução para a legibilidade dos materiais didáticos "é a mudança de postura do professor com relação ao texto didático; se ele questionar a adequação formal, o aluno poderá ver que o texto pode ser questionado tanto quanto os demais tipos" (KLEIMAN, 2011, p. 175).

\section{5. "E as respostas eram difíceis": considerações finais}

Perguntas

De acordo com os resultados da análise, pode-se atribuir quatro razões e respostas principais para a dificuldade na compreensão dos textos e dos exercícios nos materiais didáticos:

nos livros

didáticos:

1) a distância entre a linguagem utilizada nesses materiais (reforçada pelo professor) e a utilizada pelos alunos;

2) a experiência subjetiva dos alunos com a linguagem do cotidiano e a linguagem escolar: a escrita-padrão; a linguagem elaborada/ especializada associada aos campos de conhecimento;

3) a expectativa do professor ao ler as respostas dos alunos, considerando a existência (ideologia) de que sempre há um leitor-modelo e uma resposta padrão;

4) os currículos e as disciplinas escolares impostos pelo sistema de educação, baseados na monologização de saberes e linguagens e na desvalorização da pluralidade de conhecimentos tanto dos professores quanto dos alunos.

As expectativas que são construídas na escola, aquilo que se espera dos alunos, por vezes, pode criar uma relação entre professores e alunos muito tensionada, uma vez que essas expectativas geram cobranças de ambos os lados. Sabe-se que o trabalho nas escolas públicas, principalmente, da rede estadual do Rio de Janeiro, não é uma tarefa simples, as dificuldades estruturais e a carência de toda a natureza, muitas vezes, podem dificultar práticas em que o aluno seja protagonista na construção do conhecimento. Na verdade, há uma reprodução de atividades que já se mostraram pouco efetivas.

Essas expectativas estão presentes nos enunciados produzidos pelos professores, pelos livros didáticos e nas respostas construídas pelos alunos, assim não há como ter certeza se o caminho escolhido pelo professor é o mais indicado, pois "não há como prever nenhuma resposta" (SAINT' CLAIR, 2016, p. 99) 
Fernanda Bueno

Sain't Clair

Victoria Wilson

da Costa Coelho

A construção dos enunciados - sejam as perguntas da professora ou as respostas dos alunos - surge num "emaranhado hibridizado de vozes" (GOULART, 2009, p.19) que acabam por constituir os enunciados pedagógicos. Assim sendo, torna-se fundamental reconhecer essas outras vozes na construção das questões e nas respostas elaboradas pelos alunos.

Nesse sentido, o material didático, as avaliações, as respostas dos alunos, todos os elementos que compõem o cotidiano de uma sala de aula estarão sempre postos e provocando tensões. 0 modo como esse cotidiano escolar será visto, considerando que as respostas não são únicas, será diferente, como se observou na relação da professora com a turma: todos os encontros foram se construindo com afeto, respeito, e os conflitos e as tensões, antes considerados estranhos, incompreensíveis e desintegrados ao ambiente escolar, passaram a ser sentidos e vividos na dinâmica das interações. Assim, novos caminhos podem ser escolhidos, outros ângulos devem ser considerados, com a certeza de um contínuo questionamento do fazer docente.

\section{REFERÊNCIAS}

ANDRÉ, Marli Eliza Dalmazo Afonso. Campinas, São Paulo: Papirus, 1995.

ARROYO, Miguel. G. Currículo, território em disputa. 5 ed. Petrópolis: Vozes, 2011.

. Outros Sujeitos, Outras Pedagogias. Petrópolis. Vozes, 2012.

BAKHTIN, Mikhail (VOLOCHINOV). Marxismo e Filosofia da Linguagem. 7 ed. São Paulo: Hucitec, [1995], 2014.

. Estética da criação verbal. Tradução de Paulo Bezerra. 6 ed. São Paulo: Martins Fontes, [1979], 2015.

CEREJA, William Roberto; MAGALHÃES, Thereza Cochar. Português Linguagens, $6^{\circ}$ ano. $8^{\mathrm{a}}$ ed. São Paulo, Atual, 2014.

DIONNE, Hugues. A pesquisa-ação para o desenvolvimento local. Brasília: Liber Livro Editora, 2007. 
FREIRE, Paulo. Pedagogia da autonomia: saberes necessários à prática educativa. 23 ed. São Paulo: Paz e Terra, 2002.

Pedagogia do oprimido. Rio de Janeiro: Paz e Terra, 1987.

- A importância do ato de ler: em três artigos que se completam. São Paulo: Cortez, 2011.

Perguntas

GERALDI, João W. Portos de passagem. 5 ed. São Paulo: Martins Fone respostas tes, 2013.

nos livros

didáticos:

- A aula como acontecimento. São Carlos, São Paulo: Pedro \& João Editores, 2015.

A diferença identifica. A desigualdade deforma. Percursos bakhtinianos de construção ética". In. FREITAS, M.T.; JOBIM E SOUZA, S. Ciências Humanas e a Pesquisa: leituras bakhtinianas. São Paulo: Cortez, 2002.

GOULART, Cecília. O conceito de letramento em questão: por uma perspectiva discursiva da alfabetização. In: Bakhtiniana. São Paulo, v. 9, n.2, 2014, p. 35-51.

Em busca de balizadores para a análise de interações discursivas em sala de aula com base em Bakhtin. In: Revista de Educação Pública. v. 18, n. 36. Cuiabá: Universidade Federal de Mato Grosso, 2009, p. 15-31.

GUIMARÃES, Leandro. Periferia e espaços periféricos: caso do Jardim Catarina. In: Revista Pegada. Presidente Prudente.Universidade Estadual Paulista. v. 16, n.2, 2015, p. 227-249.

KLEIMAN, Ângela. Texto \& Leitor. Aspectos cognitivos da leitura. 7 ed. Campinas: Pontes, 2000.

Os significados do letramento: uma nova perspectiva sobre a prática social da escrita. Campinas: Mercado de Letras, 1995.

Leitura: ensino e pesquisa. Campinas: Pontes editores, 2011. 
$\mathrm{KOCH}$, Ingedore V.; ELIAS, Vanda. M. Ler e compreender os sentidos do texto. 3 ed. 10 reimp. São Paulo: Contexto, 2014.

. Ler e escrever: estratégias de produção textual. 2 ed. São Paulo: Contexto, 2014.

Fernanda Bueno Sain't Clair

Victoria Wilson da Costa Coelho

LIBERATO, Yara. Perguntas de 'compreensão' e 'interpretação' e o aprendizado da leitura. In. MARTINS, A., BRANDÃO, H., MACHADO, M. A escolarização da leitura literária - O jogo do livro infantil e juvenil. Belo Horizonte: Autêntica, 2007.

MARCUSCHI, Luiz Antônio. Compreensão de texto: algumas reflexões. In: O livro didático de português: múltiplos olhares. v. 2. Rio de Janeiro: Lucerna, 2003, 160p, p. 48-61.

Produção textual, análise de gêneros e compreensão. São Paulo: Parábola Editorial, 2008.

MOITA LOPES, Luis Paulo. (org.). Linguística aplicada e vida contemporânea: problematização dos construtos que têm orientado a pesquisa. In: MOITA LOPES, Luis Paulo. (org.). Por uma linguística indisciplinar. São Paulo: Parábola Editorial, 2006.

OLIVEIRA, Jair. Os sentidos da linguagem. In: Organicom. Universidade de São Paulo. São Paulo. v.5, n.9, 2008, p. 77-89.

ORLANDI. Eni Pulcinelli. Discurso e Leitura. $2^{a}$ ed. São Paulo, Cortez; Campinas, SP: Editora da Universidade Estadual de Campinas, 1993. (Coleção passando a limpo). 118 p.

Discurso e Argumentação: Um observatório político. In: Fórum Linguístico, Florianópolis, nº 1, 1998.

SAINT' CLAIR. Fernanda de Fátima Bueno. Reflexões de uma professora: dilemas e expectativas: compreensão e conhecimento nas aulas de Língua Portuguesa. Rio de Janeiro. 123 p. Dissertação (Mestrado Profissional em Letras). Faculdade de Formação de Professores, Universidade do Estado do Rio de Janeiro. São Gonçalo, 2016. 
SOBRAL, Adail. Gêneros discursivos, posição enunciativa e dilemas da transposição didática: novas reflexões. In: Letras de Hoje. v. 46, n.1.Porto Alegre, 2011, p.37-45.

STREET, Brian V. Letramentos sociais: abordagens críticas do letramento no desenvolvimento, na etnografia e na educação. São Paulo: Parábola, 2014

STUBBS, M. In: BAGNO, M., STUBBS,. M., GAGNÉ, G. Língua materna: Perguntas Letramento, variação, ensino: São Paulo: Parábola, 2002, p. 85-163. e respostas nos livros didáticos:

VOLOCHINOV, V, N. A construção da enunciação e outros ensaios. São Carlos: Pedro e João Editores, 2013.

WILSON, Victoria; MORAIS, Jacqueline de Fátima S. (org.). Leitura, escrita e ensino: discutindo a formação de leitores. São Paulo: Summus, 2015. 
